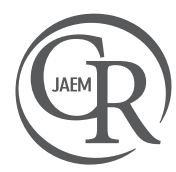

\section{Postpartum Pancreatitis}

\section{Postpartum Dönemde Pankreatit}

Emine Akıncı, Aylin Erkek

Ankara Eğitim ve Araştırma Hastanesi, Acil Servis Kliniği, Ankara, Türkiye

\section{ABSTRACT}

Pregnancy and the postpartum period are associated with many alterations in physiology, leading to challenges in the diagnosis and management of many diseases. Acute pancreatitis is rare in pregnancy and the postpartum period. In general, this is seen most often in the third trimester of the first pregnancy in young women. The most common causes are gallstones and hypertriglyceridemia. Although pancreatitis can be seen in the late stages of the pregnancy, it can also be seen in the postpartum period, and diagnosis can be difficult. This paper presents the case of a 29-year-old patient with a diagnosis of pancreatitis in the late postpartum period in the absence of other causes.

Keywords: Acute pancreatitis, postpartum period, emergency services Received: 11.06.2011 Accepted: 30.07.2011

\section{ÖZET}

Gebelik ve postpartum dönem kadınlarda bir çok fizyolojik değişikliğin olduğu ve birtakım hastalıkların tanı ve yönetiminde değişikliklere yol açan bir periyottur. Akut pankreatit gebelik ve postpartum dönemde nadir görülmektedir. Genelde sıklıkla ilk gebelikte ve 3. trimesterda ve gençlerde görülmektedir. Etiyolojisinde en sık neden safra taşları ve hipertriglisemidir. Genelde gebeliğin geç döneminde görülse de postpartum periyotta da ortaya çıkabilir ve tanı koymak oldukça güç olabilir. Bizde diğer etmenler yokluğunda gebelik sonrası geç postpartum dönemde pankreatit tanısı alan 29 yaşında hastamızı sunuyoruz.

Anahtar Kelimeler: Akut pankreatit, postpartum dönem, acil servis Geliş Tarihi: 11.06.2011 Kabul Tarihi: 30.07.2011

\section{Giriş}

Gebelik ve postpartum dönem kadınlarda birçok fizyolojik değişikliğin olduğu ve hastalıkların tanı ve yönetiminde değişikliklere yol açan bir periyottur (1). Gebelikle ilişkili pankreatit, gebelik süresince ve/veya doğumda sonraki 6 hafta içerisinde görülmektedir. Akut pankreatit gebelik ve postpartum dönemde nadir görülmektedir. Gebelikte görülen akut pankreatit ciddi mortalite ve morbiditeye neden olmaktadır (2). Genelde gebeliğin ge döneminde görülse de postpartum periyotta da ortaya çıkabilir ve tanı koymak oldukça güç olabilir (1). Bizde diğer etmenler yokluğunda gebelik sonrası geç postpartum dönemde pankreatit tanısı alan hastamızı sunuyoruz.

\section{Olgu Sunumu}

Yirmi sekiz yaşında bayan hasta bulantı, kusma, karın ağrısı şikâyetleri ile acil servise başvurdu. Anamnezinde 30 gün önce sezeryan ile doğum yaptığı, ağrııının 2 gündür artan şiddette olduğu, bugün bulantısı başladığı ardından 2 kez kustuğu ve yediklerini içerir tarzda olduğu öğrenildi. Özgeçmişinde herhangi bir hastalık öyküsü olmayan hastanın devamlı kullandığı bir ilacı yoktu. Genel durum iyi, şuur açık, oryante, koopere, TA: 90/60 mmHg, Nbz: 90/dk, Ateş: 37.1C, SS: 13/dk, GKS: 15, batın muayenesinde, C/S a ait insizyon skarı ve epigastrik hassasiyet mevcuttu. Diğer sistemlerin muayenesi doğaldı. Laboratuvar tetkiklerinde WBC:

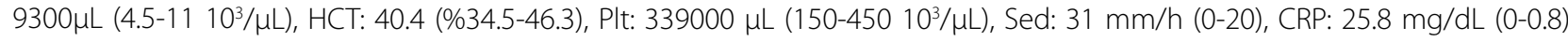
glukoz: 180 mg/dL (75-100 mg/dL), AST: 1110 U/L (0-35U/L), ALT: 520U/L (0-35U/L), ALP: 210U/L (0-35 U/L), GGT: 342 U/L (0-38 U/L), LDH: 1095U/L (0-248 U/L) Amilaz: $2790 \mathrm{U} / \mathrm{L}$ (28-128 U/L) dışında diğer tetkikler normal sınılardaydı. EKG'sinde normal sinüs ritminde olup, ST segment değişikliği yoktu. Karın ultrasonografisinde karaciğer ve safra kesesi normaldi, ancak pankreas değerlendirilemedi. Kontrastlı batın tomografisinde; pankreas boyutu hafif artmış, peripankreatik ve sol splenorenal serbest mayi mevcuttu. Parankim kuyruk kesimde hipoekoik heterojen görünümdeydi (Balthazar evre-3) (Resim 1). Hasta akut pankreatit ön tanısı 
ile dâhiliye yoğun bakıma yatırıldı. Yapılan tetkiklerinde kalsiyum: 8.7 mg/dL (8.8-10.6 mg/dL), trigliserid: 58 mg/dL (50-200 mg/dL), kolesterol: $130 \mathrm{mg} / \mathrm{dL}$ (110-200 mg/dL), LDL: 76 mg/dL (60-130 mg/dL), Lipaz: 170 U7 It (<60 U7It) HbsAg (-), AntiHBs (-), HCVAg (-), AntiHIV $(-)$, Anti HAV IgG (+), IgM (-), CMV IgM (-), EBV IgM (-) ölçüldü. Hastada etiyolojide postpartum pankreatit düşünüldü. Seftriakson 2x1 gram intravenöz ve sıvı tedavisine başlandı. Kan amilaz değerleri 2. ve 3 . günde sırasıyla, $230 \mathrm{U} / \mathrm{L}$ ve $120 \mathrm{U} / \mathrm{L}$ olan hastanın genel durumda düzelme, semptomlarda gerileme olması ve laboratuvar değerlerinin 7. günde tamamen normal düzeylere inmesi üzerine taburcu edildi.

\section{Tartışma}

Akut pankreatit, pankreatik enzimlerin hücre dışına çıkması sonucu otodigesyon ile kendini gösteren, karın ağrısı ile başlayan, kan ve idrarda pankreas enzimlerinin yüksekliği ile seyreden inflamatuvar bir durumdur (3). Etiyolojisinde safra taşları ve alkolizm ilk iki sırada yer almaktadır. Gebelikte akut pankreatit birlikteliği nadir görülmektedir. Gebelerde görülme sıklığı yaklaşık 1/10000 civarındadır (4). Genelde ilk gebelikte ve gençlerde sıktır (5). Gebelik ayı ilerledikçe safra kesesi hastalıkları insidansı da artmaktadır. Buna paralel olarak akut pankreatit en sık 3. trimesterda görülmektedir (6). Ramin ve arkadaşlarının (7) 43 vakadan oluşan araştırmasında, sadece birkaç olgunun doğumdan sonraki dönemde görüldüğünü bildirilmiştir. Pankreatitin klinik bulguları gebelikte de aynıdır. Karın ağrısı, bulanı kusma sık görülmektedir. Ancak özellikle ilk trimesterde olan vakalar hiperemezis gravidarumla karışabilir ve hastalar sıklıkla atlanabilirler.

Gebelik ve post partum periyotta görülen akut pankeatit etiyolojisi genel populasyonla benzerdir. Gebelerde akut pankreatitin en sık nedeni kolelitiyazistir. Bunun yanı sıra gebelikte hipertrigliseridemiye, ilaçlara bağlı ve idiyopatik pankreatit de görülebilirken alkole bağlı pankreatit oldukça nadirdir (4)

Hastamızda kolelityazis, hipertriglisemi, alkol, ilaç öyküsü yoktu. Gebelikte safra içeriği, safra kesesi kontraktilitesinde değişiklikler olmakta böylece gebelik süresince safra kesesinde taş ve çamur oluşumuna yatkınlık artmakta ve bu durum akut pankreatit için zemin hazırlamaktadır. Gebelikte 2. ve 3. trimesterda, hepatik safra içerisindeki kolesterol sekresyonu; safra asitleri ve fosfolipidlerle karşılaştırıldığında daha fazla artmaktadır. Açlıkta ve postpandiyal dönemde safra volümü ve kese hacmi artarken, hormonal değişikliklere bağlı safra boşalma hızı azalmaktadır (6). Özellikle son trimesterde yüksek östrojen seviyelerine bağlı hepatik

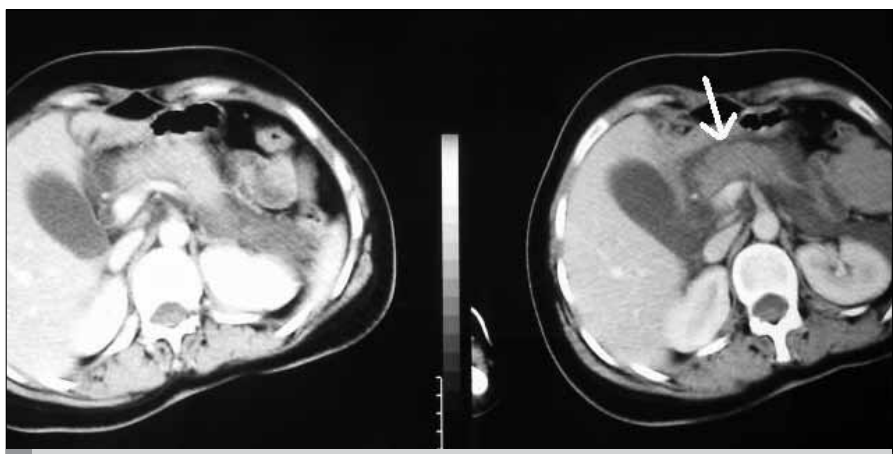

Resim 1. Pankreas boyutu hafif artmış, peripankreatik ve sol splenorenal serbest mayi (beyaz ok) safra içeriği değişmekte, yüksek progesterona bağlı motilite azalmakta ve rezidü safra miktarı artmaktadır (8). Özellikle kolesterolden zengin süpersature rezidü safra, kolesterol kristallerine ve zaman geçtikçe taş oluşumuna neden olmaktadır (6). Gebelik süresince oluşan minik safta taşları veya çamur, doğumdan sonra yine safra kompozisyonu ve kese motilitesindeki değişikler yüzünden kaybolabilir. Hastamızda görülen pankreatitin bu zeminde gelişmiş olabilir.

Gebelikte ve postpartum dönemde akut pankreatit tedavisi gebe olmayan olgular gibidir. Tedavi öncelikle medikaldir. Sıvı replasmanı, oksijen, analjezi, antibiyotik, nazogastrik dekompresyon, total parenteral nutrisyonu içeren destek tedavisi içerir (4). Hastaların büyük çoğunluğunda tedavi ile düzelme olmakta, hastalık spontan olarak sınırlanmaktadır. \%0.05-\%0.8 olguda pankreas nekrozu ile lokal ve sistemik komplikasyonlar oluşmaktadır (9). Eski yayınlarda maternal ve fetal mortalite oranları (\%20-\%50) oldukça yüksek olarak belirtilse de abdominal görüntüleme yöntemlerindeki ilerleme ve daha az invazif tekniklerin kullanılması ile bu oranlar günümüzde oldukça azalmıştır (7, 10). Hernandez ve Date'in vaka serilerinde fetal kayıp oranları \%4.7-\%2.1 arasında değişmekteyken, pankreatit ve komplikasyonlarına bağlı maternal mortalite bildirilmemiştir $(11,12)$.

\section{Sonuç}

Gebelikte ve doğum sonrası dönemde karın ağrısı ile başvuran hastaların değerlendirilmesinde çok sık görülmese de, akut pankreatit tanısı dikkate alınmalıdır.

\section{Çıkar çatışması}

Yazarlar herhangi bir çıkar çatışması bildirmemişlerdir.

\section{Kaynaklar}

1. Hernandez A, Petrov MS, Brooks DC, Banks PA, Ashley SW, Tavakkolizadeh A. Acute pancreatitis and pregnancy: a 10-year single center experience. J Gastrointest Surg 2007; 11: 1623-7. [CrossRef]

2. Turhan AN, Gönenç M, Kapan S, Islim F, Oner OZ, Tulubaş E, et al. Acute biliary pancreatitis related with pregnancy: a 5-year single center experience. Ulus Travma Acil Cerrahi Derg 2010; 16: 160-4.

3. Akıncı E, Kocaşaban DU Coşkun F. Yüksek Doz Naproksen Alımına Bağlı Akut Pankreatit Olgusu. Turk J Emerg Med 2010; 10: 191-3.

4. Çelik Ç, Gezginç K, Acar A, Aksoy F, Akyürek C. Gebelikte akut pankreatit: Bir olgu sunumu. T Klin Jinekol Obst 2002; 12: 475-7.

5. Maringhini A, Lankisch MR, Zinsmeister AR, Melton LJ 3rd, DiMagno EP. Acute pancreatitis in the postpartum period: a population-based casecontrol study. Mayo Clin Proc 2000; 75: 361-4. [CrossRef]

6. Pitchumoni CS, Yegneswaran B. Acute pancreatitis in pregnancy. World J Gastroenterol 2009; 15: 5641-6. [CrossRef]

7. Ramin KD, Ramin SM, Richey SD, Cunningham FG. Acute pancreatitis in pregnancy. Am J Obstet Gynecol 1995; 173: 187-91. [CrossRef]

8. Pandey M, Shukla VK. Lifestyle, parity, menstrual and reproductive factors and risk of gallbladder cancer. Eur J Cancer Prev 2003; 12: 269-72. [CrossRef]

9. Ko CW. Risk factors for gallstone-related hospitalization during pregnancy and the postpartum. Am J Gastroenterol 2006; 101: 2263-8. [CrossRef]

10. Joupilla P, Mokka R, Larmi TKI. Acute pancreatitis in pregnancy. Surg Gynaecol Obstet 1974; 139: 879-82

11. Hernandez A, Petrov MS, Brooks DC, Banks PA, Ashley SW, Tavakkolizadeh A. Acute pancreatitis and pregnancy:a 10-year single center experience. J Gastrointest Surg 2007:11:1623-7. [CrossRef]

12. Date RS, Kaushal M, Ramesh A. A review of the management of gallstone disease and its complications in pregnancy. Am J Surg 2008; 196 : 599-608. [CrossRef] 